\title{
Emilia Murry Ramey and Jody John Ramey: Autistics' Guide to Dating: A Book by Autistics, for Autistics and Those Who Love Them or Who Are in Love with Them
}

\author{
Jessica Kingsley Publishers, London, 2008, 125 pp, \$19.95 (paper)
}

\author{
Lawrence A. Vitulano • Michael L. Vitulano
}

Published online: 14 December 2010

(C) Springer Science+Business Media, LLC 2010

Autistics' Guide to Dating: A Book by Autistics, for Autistics and Those Who Love Them or Who Are in Love with Them is a respectful and gentle book that offers hope and practical guidance to young adults on the autism spectrum and to their parents as these individuals prepare for successful dating and committed relationships. Emilia and Jody Ramey are a young and courageous married couple on the autism spectrum who like to tell stories. They are funny and typical in many ways as they describe revealing experiences about their own lives and the challenges they have had to face to get where they are today. The Rameys are college educated, creative and teach various forms of dance and choreography to people with and without disabilities. The goal of this book is to help other young adults on the spectrum prepare for their own struggles which they will face as people seeking loving relationship while overcoming their own challenges. Based on our clinical experiences, this book in fact will help many Autistic people, who are too often misunderstood, develop more meaningful relationships and live more enjoyable lives.

The anecdotes presented by the Rameys are moving personal accounts of successes and failures, and their hopeful "you can do it" approach is infectious. The authors openly discuss their own vulnerabilities in order to serve as teachers for others. Their methodology works. They break down dating, courting and friendship to their fundamental

\footnotetext{
L. A. Vitulano $(\bowtie)$

Yale Child Study Center, Yale School of Medicine, 230 South Frontage Road, New Haven, CT 06520, USA

e-mail: lawrence.vitulano@yale.edu
}

M. L. Vitulano

Department of Psychology, Dr. Paula Fite's Lab,

University of Tennessee, Knoxville, TN 37996, USA

e-mail: mvitulan@utk.edu elements and propose a roadmap to successful and healthy relationships. Their emphasis is on learning how to get close to another person, one step at a time, and appreciating individual differences and preferences. This "How To" book is a broadly applicable manual for success. It provides many suggestions for positive socializing which also could be useful to many individuals who are not even on the spectrum but struggling with meeting and making friends. Creating successful first impressions and following the six steps to success in the world of dating provided in a worksheet format were especially instructive, well-presented hints for both teachers and young adults. The transitions from friendships to dating to physical intimacy are sensitively and openly discussed in a clear, candid and easily comprehensible style. Individual differences and sensory preferences are respectfully considered, along with many recommendations for managing tricky demands from someone you like but are not ready to love. Individuals who feel that many of the communication and other social demands in relationships are difficult and that the skills that they require don't come so naturally will find this book comforting. They will discover strategies to overcome some of their deficits along with the encouragement to keep working at it. Social skill deficits and sensory issues such as personal space, eye-contact, touching, and much more are addressed with sound advice and practical remedies. We strongly recommend this short, humorous, encouraging and delightful book as a must read for Autistic people in search of a meaningful love relationship and also for those people who love them or are in love with them. 